\title{
Study of the crystallographic texture of pipe steel
}

\author{
B. S. Ermakov ${ }^{1}$, A. A. Alhimenko ${ }^{1}$, N. O. Shaposhnikov ${ }^{1}$, A. S. Tsvetkov ${ }^{\dagger, 1}$, A. V. Shirokov ${ }^{2}$ \\ †a.s.tsvetkow@gmail.com
}

${ }^{1}$ Peter the Great Saint Petersburg Polytechnic University, 29 Polytechnicheskaya St., St. Petersburg, 195251, Russia

${ }^{2}$ Severstal, 2 Klara Tsetkin St., Moscow, 127299, Russia

In the manufacture of large-diameter welded pipes used for the construction of pipelines operating at high pressure, it is extremely important to provide the required mechanical and service characteristics. One of the main tasks of improving the quality of each batch of sheet metal, while maintaining or reducing the cost of production of pipes, is to provide a set of mechanical properties. The problems of obtaining proper mechanical characteristics of sheet products of the widely used 10G2FB steel during its production have been raised for several years. This is explained by the facts that this steel is still used in the construction of trunk pipelines and the technological process for the production of rolled products is a multi-factor system, the accomplishment of each stage of which directly affects the quality. In this paper, we consider issues related to the study of the texture state of samples cut from 6 pipes (from different batches, different manufacturers) made of 10G2FB lowcarbon steel in order to construct direct and inverse pole figures and determine the role of texture formation in the properties of the base metal. A comparative analysis of the obtained results of mechanical tests is carried out. A comparison of the test results for impact toughness and crack resistance with the results of texture analysis showed that pipe samples, in the structure of which after rolling the textures were formed, which were determined as maximum when controlling reflections from a series of planes (110), showed the best viscous properties in low temperature impact bending tests and in the entire range of studies in tests for crack resistance.

Keywords: pipeline, steel 10G2FB, crystallographic texture, strength properties, crack resistance.

УДК: 669.01:621.643

\section{Исследование кристаллографической текстуры трубной стали}

\author{
Ермаков Б. С. ${ }^{1}$, Альхименко А. А. ${ }^{1}$, Шапошников Н. О. ${ }^{1}$, Цветков А. С. ${ }^{\dagger, 1}$, Широков А. В. ${ }^{2}$ \\ ${ }^{1}$ Санкт-Петербургский политехнический университет Петра Великого, ул. Политехническая, 29, \\ С.-Петербург, 195251, Россия \\ ${ }^{2}$ Северсталь, ул. Клары Цеткин, 2, Москва, 127299, Россия
}

При изготовлении сварных труб большого диаметра, предназначенных для строительства магистральных трубопроводов, работающих при повышенном давлении, крайне важно обеспечить требуемые механические и служебные характеристики. Одной из основных задач повышения качества каждой партии листового проката, при сохранении или понижении себестоимости производства труб, является обеспечение комплекса механических свойств. Проблемы формирования механических характеристик листового проката из широко используемой стали 10Г2ФБ в процессе его производства поднимаются не первый год. Объясняется это как тем, что данная сталь до сих пор применяется при строительстве магистральных трубопроводов, так и тем, что технологический процесс производства проката представляет собой многофакторную систему, исполнение каждого этапа которой напрямую влияет на качество. В настоящей работе рассмотрены вопросы, связанные с исследованием текстурного состояния образцов, вырезанных из 6 труб (из разных партий, разных производителей), изготовленных из низкоуглеродистой стали 10Г2ФБ, с целью построения прямых и обратных полюсных фигур и определения роли текстурообразования в формировании свойств основного металла. Проведен сравнительный анализ полученных результатов механических испытаний. Сопоставление результатов испытаний на ударную вязкость и трещиностойкость с результатами текстурного анализа показал, что образцы труб, в структуре которых после прокатки были сформированы текстуры, определяемые при контроле 
отражений от серии плоскостей (110) как максимальные, показали наилучшие вязкие свойства при низкотемпературных испытаниях на ударный изгиб и во всем диапазоне исследований при испытаниях на трещиностойкость.

Ключевые слова: трубопровод, сталь 10Г2ФБ, кристаллографическая текстура, прочностные свойства, трещиностойкость.

\section{1. Введение}

В силу своего географического положения Россия является страной обладающей запасом углеводородного сырья и активно его разрабатывающей. Соответственно, в стране имеется разветвленная сеть нефте- и газопроводов, работающих в различных климатических условиях и обслуживающих добычу, переработку и транспортировку продукта. Необходимость реконструкции действующих и прокладки новых трубопроводов в значительной степени определяет темп развития трубного сегмента металлургической отрасли. Вопросы металлургического качества листового проката и трубной продукции [1-3], а также обеспечения однородности механических характеристик труб и их соединений, несомненно, актуальны.

Увеличение диаметра и давления, толщины стенки труб, освоение месторождений в северных широтах, усовершенствование сварочных технологий, вызвали изменения не только в требованиях к механическим показателям и химическому составу трубных сталей, но и к технологии изготовления листового и рулонного штрипса, процессам формовки труб, а также физическим средствам контроля качества продукции.

Показатели качества труб, производимых формовкой в профилегибочных агрегатах из рулонного горячекатаного проката, изготавливаемого на широкополосных станах, определяются, прежде всего, исходными показателями качества проката [4]. К прокату предъявляются требования хорошей свариваемости, высокой прочности и вязкости, удовлетворительных пластических свойств и относительно невысокой цены $[5,6]$. Этим требованиям отвечают низкоуглеродистые и низколегированные стали [7], такие как 10Г2ФБ.

Разработка и оптимизация технологического процесса изготовления листового проката для труб большого диаметра, требует достоверных сведений об основных характеристиках обрабатываемой стали. Кроме химического состава к таким характеристикам относятся данные о положении критических точек [8], кинетике распада переохлажденного аустенита $[9,10]$, а также о процессах рекристаллизации [11] и кристаллографической текстуре трубной стали [12,13], в частности для контроля технологии прокатки, и др.

Пластическая деформация металла приводит к формированию текстуры. Результаты изучения изменения кристаллографической текстуры используются при исследовании развития слоисто-хрупких трещин [14], приводящих к наступлению аварийных ситуаций и возможному разрушению трубопровода. Процессы, происходящие в материале при его технологической обработке, приводят к изменению ориентировки кристаллитов и изменению дифракционной картины, заключающемуся в изменении распределения интенсивности в дифракционном спектре.

\section{2. Материал для исследования и методика испытаний}

Для исследования кристаллографической текстуры трубной стали 10Г2ФБ из 6 прямошовных сварных труб большого диаметра для магистральных трубопроводов (группа прочности Х65) были вырезаны темплеты и изготовлены образцы (условные номера $1 \div 6$ ). Трубы имели одинаковый диаметр (1020 мм) и примерно равную толщину ( $15 \pm 1$ мм). Химический состав всех труб с небольшими отклонениями удовлетворял следующему, мас.\%: C $0.095 ; \quad \mathrm{Si} 0.34 ; \mathrm{Mn}$ 1.49; $\sum(\mathrm{V}+\mathrm{Nb}+\mathrm{Ti})$ 0.13; S 0.025; P 0.015. Микроструктура основного металла труб состояла из феррито-перлитной смеси с содержанием перлитной фазы не более $15 \%$. Анализ микроструктуры основного металла всех труб был проведен на шлифах в соответствии с требованиями ГОСТ 5639 на оптическом металлографическом микроскопе ZeissAxio. В структуре присутствуют мелкие неметаллические включения (оксиды и сульфиды кальция, алюминия и кремния), статистически распределенные в объеме.

Исследования кристаллографического состояния трубной стали были выполнены на многофункциональном рентгеновском дифрактометре Rigaku Ultima IV. Дифрактометр снабжен комплексом управляющих программ и обрабатывающим комплексом PDXL (X-ray Powder Diffraction Software) с базой стандартов PDF-2 и программным комплексом для анализа текстур LaboTex 3.0. Полученные данные являются усредненными значениями исследования трех образцов на одну точку контроля. Текстурный анализ основного металла всех труб проводился с помощью программы исследования текстур методом Шульца (на отражение). Анализ проводился для отражений от серий плоскостей (110), (200) и (211). Для получения нормированных ППФ и ОПФ [15], был снят эталонный бестекстурный (порошкообразный) образец $\alpha-\mathrm{Fe}$.

Для испытаний на ударный изгиб были изготовлены поперечные стандартные образцы размером $10 \times 10 \times 55$ мм и глубиной надреза 2 мм (тип 11 по ГОСТ 9454). Надрезы были выполнены перпендикулярно к прокатной поверхности металла. Испытания проводились на маятниковом копре INSTRON 600MPX.

Испытания образцов из основного металла на трещиностойкость выполнялись на стандартных образцах прямоугольной формы типа SENB с помощью испытательного оборудования INSTRON 8801 с использованием экстензометров INSTRON C.O.D. Gauge 2670-122 (при подготовительных испытаниях - циклических нагружениях для усталостных увеличений длин надрезов) и EPSILON C.O.G. 3541-010-100M-LHT (при основных испытаниях - статических нагружениях для определения критических величин раскрытия вершин трещин CTOD), а также камеры для обеспече- 
ния заданной отрицательной температуры. Определение длины фактической трещины в образце выполнялось с помощью измерительного комплекса ZEIZZ O-INSPECT 442 и программного обеспечения CALYPSO.

\section{3. Результаты исследований и их обсуждение}

К факторам, определяющим формирующуюся при прокатке текстуру, относятся величина обжатий при прокатке, действие трения между валками и листом, температура нагрева и пр. Формирование текстуры происходит при деформации в основном под действием напряжений вследствие скольжения дислокаций. В различных слоях проката реализуются различные напряженные состояния: центральные слои подвергаются действию растягивающих напряжений, поверхностные - сжимающим.

Рентгеноструктурный фазовый анализ, проведенный по обзорным съемкам 6 исследуемых образцов, снятых в области брэгговских углов дифракции $(3-154)^{\circ} 2 \theta$, выявил наличие фазы с ОЦК-решеткой, идентифицируемой ферритом ( $\alpha-\mathrm{Fe})$ с распределением интегральных интенсивностей дифракционных максимумов, близким к эталонным значениям. Результаты контроля представлены на Рис. 1.

Текстура трубной заготовки может включать в себя самые разные ориентировки: текстуру сдвига $\{110\}<001>$, набор текстур плоской деформации а-фазы и набор текстур, характерный для фазового превращения текстурованной $\gamma$-фазы. Основными ориентировками текстуры, характерной для плоской деформации а-фазы при прокатке, являются: $\{001\}<110>,\{112\}<110>-$ основные, и $\{111\}<110>,\{111\}<112>-$ дополнительные. В ходе $\alpha$-превращения без нагрузки образуются ориентировки: $\{001\}<110>,\{337\}<110>,\{554\}<225>$ и $\{113\}<110>$. В результате превращения под нагрузкой возможно образование $[9,16] \quad$ ориентировок: $\{410\}<283>$,

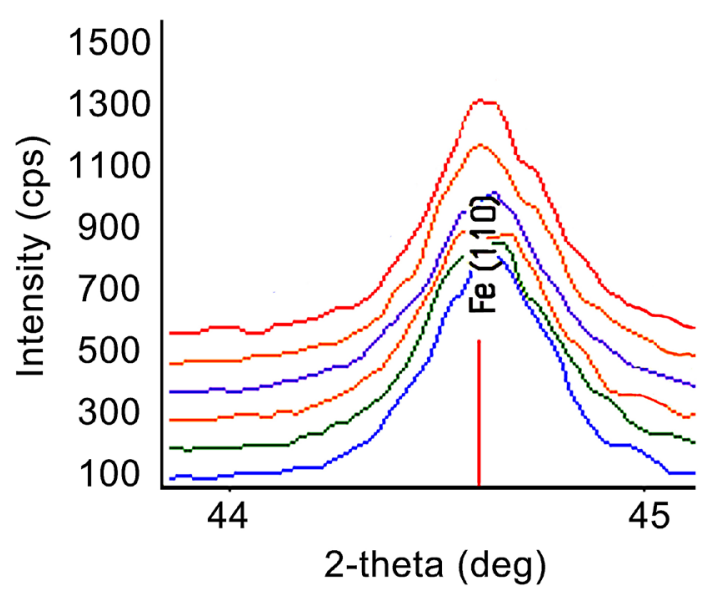

Pис. 1. (Color online) Сводный график участка обзорных дифрактограмм образцов, отвечающих дифракционному отражению $\alpha-\mathrm{Fe}$ от серии плоскостей (110). Нумерация образцов идет снизу вверх.

Fig. 1. (Color online) A consolidated graph of the area of survey diffraction patterns of samples corresponding to the $\alpha$-Fe diffraction reflection from a series of planes (110). Sample numbering goes from bottom to top.
$\{610\}<166>,\{634\}<283>$ и $\{750\}<10.14 .5>$. Однако в нашей работе при исследовании основного металла труб эти ориентировки обнаружены не были. Исследования были проведены в двух сечениях по толщине трубы в $1 / 4$ и $1 / 2$ от наружной поверхности трубы. Описание текстуры в материале осуществлено с помощью прямых полюсных фигур (ППФ) и обратных полюсных фигур (ОПФ), являющихся стереографическими проекциями нормалей отражающих плоскостей одного типа $\{\mathrm{hkl}\}$. ППФ и ОПФ характеризуются теми идеальными ориентировками, которым соответствуют наиболее интенсивные максимумы. Кривые зависимости суммарной интенсивности от угла наклона образца а (текстурограммы), для исследуемой серии образцов, наглядно иллюстрируют характер текстуры и количественные соотношения между различными компонентами текстуры и ее бестекстурной составляющей, а также показывают изменения текстуры под влиянием различных технологических факторов [12,13]. Текстурограммы исследуемых образцов приведены на Рис. 2 и 3.

При анализе текстурограмм установлено, что для отражений от серии плоскостей (110) в основном металле труб с условными номерами 4 и 5 наблюдается некоторое усиление текстуры прокатки. Для образцов 2 и 6 в меньшей степени, для остальных - состояние, близкое к бестекстурному.

По результатам обработки данных посредством построения ППФ и их полуколичественного анализа были выделены следующие основные ориентировки: $\{112\}<110>,\{001\}<100><110>,\{110\}<001>,\{111\}<110><112>$, $\{113\}<110>$, относящиеся к текстурам деформации а-фазы, а также ее превращения.

Полуколичественный анализ ППФ от линий (110), (200) и (211) образцов от двух образцов 4 и 5 в плоскости $\mathrm{HH}$ (ND) дал следующее распределение процентного содержания этих ориентировок: сталь трубы 5 ориентировка $\{110\}<001>$ в $1 / 2-14 \%$ - остальное бестекстурная компонента; в $1 \frac{1}{4}-11 \%$; в стали трубы 4 ориентировка $\{110\}<001>$ в $1 \frac{2}{2}-14.2 \%$ - остальное бестекстурная компонента; в $1 / 4-10.5 \%$.

По представленным результатам видно, что доля бестекстурной компоненты, то есть части с равномерным распределением всех ориентировок больше в сечении, взятом с $1 / 4$ по толщине трубы, чем в ее середине, где текстура более выражена. В образцах остальных труб доля текстурной ориентировки $\{110\}<001>$ еще менее заметна.

Наибольшие доли содержания текстурных ориентировок для отражений от серии плоскостей (110) обнаружены в образцах основного металла труб 4 и 5. В основном металле труб 2 и 6 доля содержания текстурных ориентировок для отражений от серии плоскостей (110) выражена в меньшей степени, для остальных сталей труб - состояние, близкое к бестекстурному. На глубине 1/4 стенки труб от наружной поверхности распределение ориентировок, в основном, более равномерное.

На поверхности металл в большей степени приближен к бестекстурному состоянию, то есть нормальному распределению всех ориентировок. Для отражений 

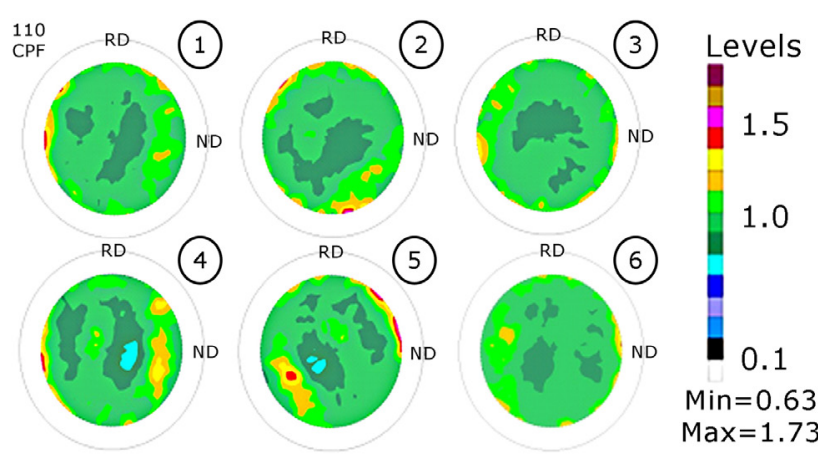

a
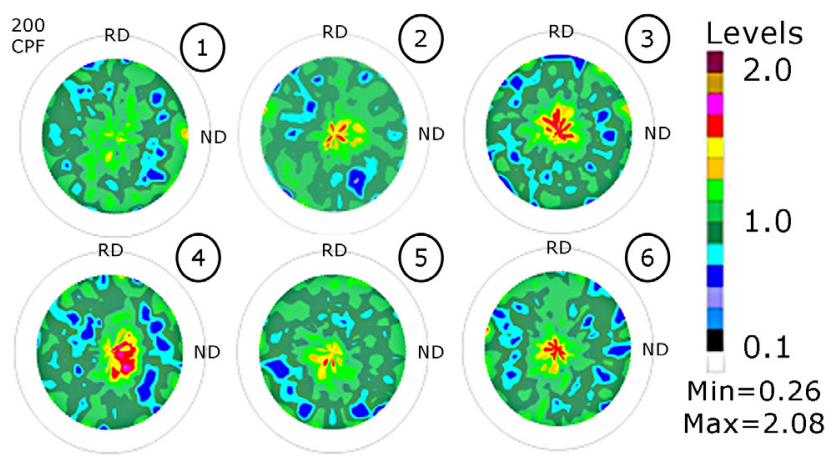

b
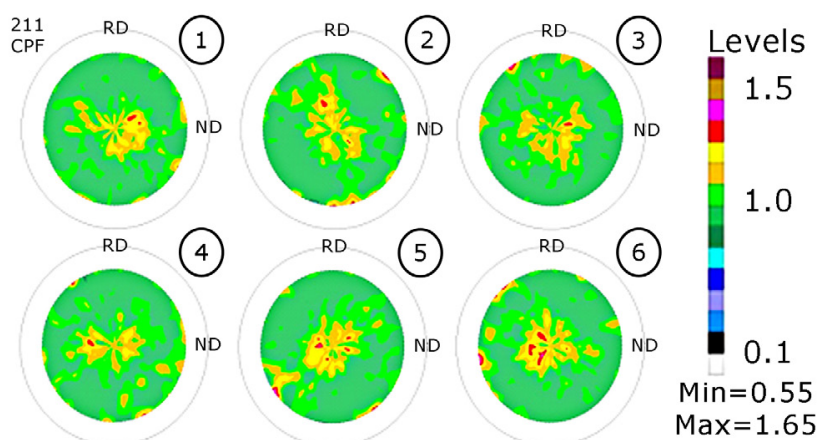

C

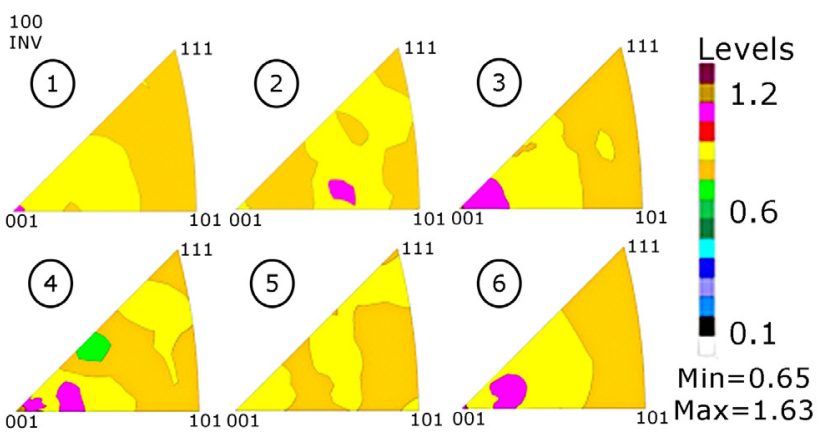

a
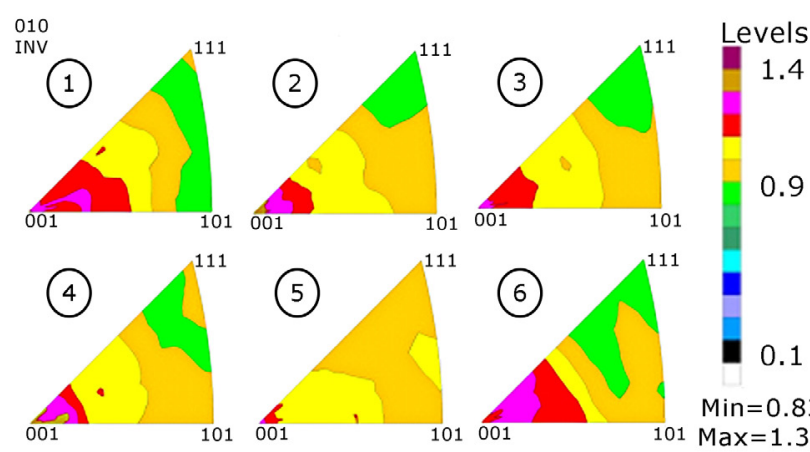

b
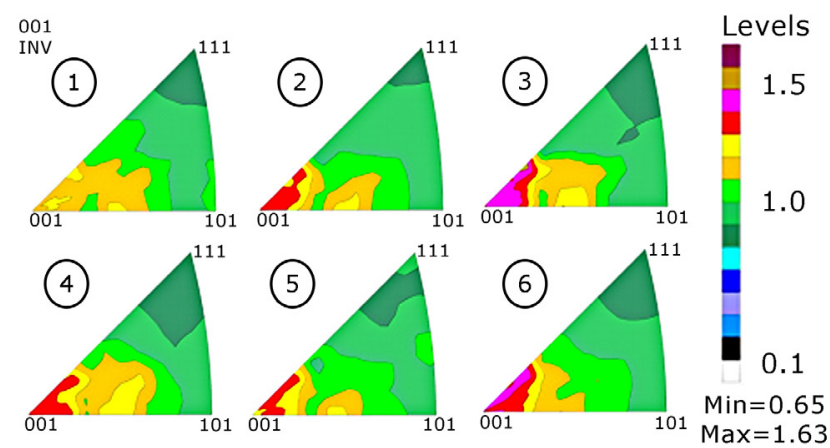

$c$

Pис. 3. (Color online) ОПФ основного металла труб (1...6 условный номер): $\{110\}$ (a); $\{200\}$ (b); $\{211\}$ (c).

условный номер): $\{110\}$ (a); $\{200\}$ (b); $\{211\}$ (c).

Fig. 2. (Color online) $\mathrm{CPF}$ of the base metal of pipes (1..6 conditional number): $\{110\}$ (a); $\{200\}$ (b); $\{211\}$ (c).

(200) и (211) явных отличий между основным металлом всех труб не выявлено, а процент присутствия этих ориентировок крайне мал.

Металл всех исследованных труб, может быть представлен в виде трех основных групп: $1-$ с явно выявленной текстурой прокатки при контроле отражений от серии плоскостей (110): образцы труб 4 и 5; 2 - со слабо выраженной текстурой прокатки: образцы труб 2 и 6; 3 - в бестекстурном состоянии: образцы труб 1 и 3.

На Рис. 4 представлена типичная микроструктура исследованных сталей при увеличении $\times 500$. Следует отметить замеченную в ходе исследований разнозернистость. Средний размер зерен в сталях труб 1-6 колеблется в интервале 11-19 мкм (G10-G12 по ГОСТ 5639). На всех исследованных микрошлифах
Fig. 3. (Color online) INV of the base metal of pipes (1... $6-$ conditional number): $\{110\}$ (a); $\{200\}$ (b); $\{211\}$ (c).

также отмечена значительная полосчатость структуры, которую в соответствии с ГОСТ 5640 можно охарактеризовать 4-5 баллом для труб 1 и 3, 3-4 баллом для труб 2 и 6, 2-3 баллом для труб 4 и 5. Доля ферритной составляющей видимой площади шлифа $85 \%$. Также было установлено, что микролегирующие добавки ванадия, титана и ниобия частично растворены в твердом растворе сталей, а частично находятся в составе неметаллических включений. Отдельных включений простых карбидов или карбонитридов типа МеC или $\mathrm{MeCN}$ не обнаружено в структуре ни одной из труб.

В Табл. 1 приведены результаты испытаний на ударный изгиб основного металла исследованных труб при температурах -5 и $-60^{\circ} \mathrm{C}$, позволяющие оценить роль текстуры материала в формировании свойств листовой заготовки. 

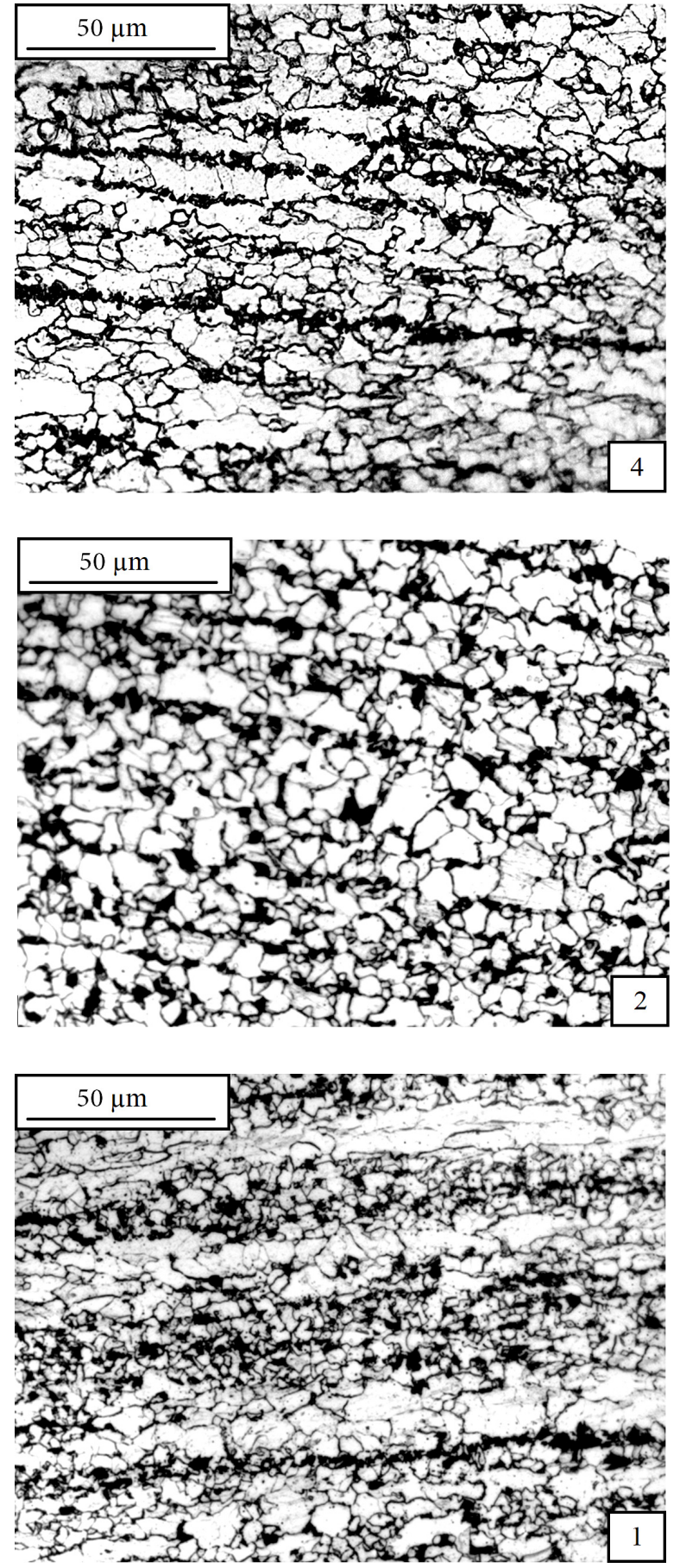
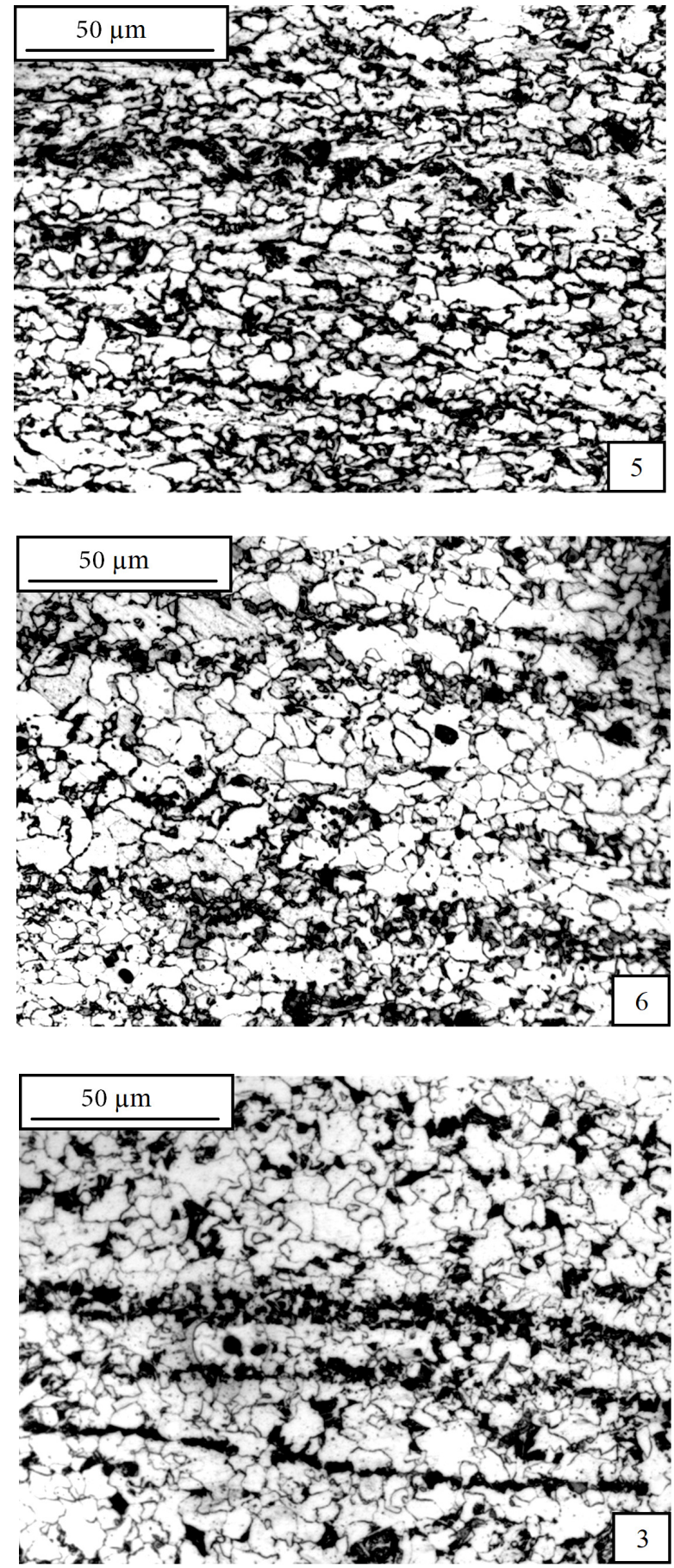

Рис. 4. Микроструктура основного металла труб (1...6 - условный номер).

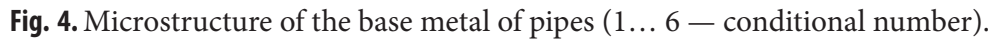

Табл. 1. Влияние текстурного состояния на формирование свойств основного металла труб.

Table 1. The effect of the texture state on the formation of properties of the base metal of pipes.

\begin{tabular}{|c|c|c|c|c|c|}
\hline \multirow{2}{*}{$\begin{array}{l}\text { Группа } \\
\text { Group }\end{array}$} & \multirow{2}{*}{$\begin{array}{l}\text { Номер трубы } \\
\text { Pipe number }\end{array}$} & \multicolumn{2}{|c|}{$\begin{array}{c}\text { Ударная вязкость, Дж/см² } \\
\text { Toughness, J/sm² }\end{array}$} & \multicolumn{2}{|c|}{$\begin{array}{l}\text { Трещиностойкость, CTOD min, мм } \\
\text { Crack resistance, CTOD min, mm }\end{array}$} \\
\hline & & $-5^{\circ} \mathrm{C}$ & $-60^{\circ} \mathrm{C}$ & $-10^{\circ} \mathrm{C}$ & $-20^{\circ} \mathrm{C}$ \\
\hline \multirow{2}{*}{1} & 4 & 325 & 298 & 0.79 & 0.75 \\
\hline & 5 & 395 & 339 & 0.79 & 1.01 \\
\hline \multirow{2}{*}{2} & 2 & 307 & 133 & 0.52 & 0.62 \\
\hline & 6 & 317 & 186 & 0.37 & 0.46 \\
\hline \multirow{2}{*}{3} & 1 & 172 & 133 & 0.32 & 0.48 \\
\hline & 3 & 187 & 129 & 0.11 & 0.61 \\
\hline
\end{tabular}


На основании приведенных данных становится очевидным, что образцы труб, в структуре которых после прокатки были сформированы текстуры, определяемые при контроле отражений от серии плоскостей (110) как максимальные, в данном исследовании, показали наилучшие механические свойства во всем диапазоне исследований. Соответственно, при повышении уровня текстурной ориентации вязкие свойства основного металла труб также повышаются.

\section{4. Выводы}

Основным технологическим направлением в прокатном переделе на сегодняшний момент является контролируемая прокатка. Для разработки и оптимизации прецизионного исполнения технологии термодеформационной обработки применяется в частности анализ кристаллографической текстуры.

В представленной работе рассмотрены вопросы, связанные с исследованием текстурного состояния трубной стали. В статье приведены результаты исследования текстурного состояния металла 6 труб с целью построения прямых и обратных полюсных фигур и определения роли текстурообразования в формировании механических свойств основного металла трубной стали.

На основании проведённых исследований кристаллографической текстуры было установлено, что текстурограммы образцов, взятых из одного участка труб из стали 10Г2ФБ, но с разной глубины по толщине, существенно отличаются друг от друга. Это отличие выражается, прежде всего, в том, что в центральных слоях имеется усиление ориентировок текстуры сдвига (110) и уменьшение угла рассеяния текстур. В центре стенок труб сохраняется текстурная ориентировка для отражений от серии плоскостей (110); ближе к поверхности металл в большей степени приближен к бестекстурному состоянию, то есть нормальному распределению всех ориентировок. Для отражений (200) и (211) явных отличий между основным металлом всех труб не выявлено, а процент присутствия этих ориентировок в металле крайне мал.

Сравнительный анализ микроструктур показал, что структура стали всех труб практически идентична и представляет собой структуру полигонального феррита и перлита. Отмечена разнозернистость и значительная полосчатость структуры. Сопоставление результатов испытаний на ударную вязкость и трещиностойкость с результатами текстурного анализа показал, что образцы труб, в структуре которых после прокатки были сформированы текстуры, определяемые при контроле отражений от серии плоскостей (110) как максимальные, показали наилучшие вязкие свойства при низкотемпературных испытаниях на ударный изгиб и во всем диапазоне исследований при испытаниях на трещиностойкость.

\section{Литература/References}

1. S. Y. Kondrat'ev, O. V. Shvetsov. Metal Science and Heat Treatment. 60 (1-2), 32 (2018). $\underline{\text { Crossref }}$

2. B.S. Ermakov, N.O. Shaposhnikov. Metallurgist. 62 (7-8), 766 (2018). Crossref

3. Yu. V. Podolsky. Petroleum Geology. Neftegazovaya Geologiya. Teoriya I Praktika. 3 (4), 84 (2008). (in Russian) [Ю.В. Подольский. Нефтегазовая геология. Теория и практика. 3 (4), 84 (2008).]

4. I. G. Rodionova, A. V. Mitrofanov, S.M. Tihonov et al. Inzhenernaya praktika. 12 (2017). (in Russian) [И.Г. Родионова, А.В. Митрофанов, С. М. Тихонов и др. Инженерная практика. 12 (2017).]

5. H. Kinoshita, T. Wada, R. Ando et al. Novosti chernoy metallurgiya za rubezhom. 3, 44 (2005). (in Russian) [Х. Киношита, Т. Вада, Р. Андо и др. Новости черной металлургия за рубежом. 3, 44 (2005).]

6. S.L. Zhdanov, V.D. Pozdnyakov, A.A. Maksimenko et al. Avtomaticheskaya Svarka. 11, 12 (2010). (in Russian) [С. Л. Жданов, В. Д. Позняков, А. А. Максименко и др. Автоматическая сварка. 11, 12 (2010).]

7. Y.P. Solncev, B.S. Ermakov et al. Metally i splavy. Handbook (ed. by Y.P. Solncev). St. Petersburg, Professional (2005). 998 p. (in Russian) [Ю.П. Солнцев, Б.С. Ермаков и др. Металлы и сплавы. Справочник. (под общ. ред. Ю.П. Солнцева). С.-Петербург, Профессионал (2005) 998 с.]

8. I. V. Teplukhina, V.M. Golod, A.S. Tsvetkov. Letters on Materials. 8 (1), 37 (2018). (in Russian) [И. В. Теплухина, В. М. Голод, А. С. Цветков. Письма о материалах. 8 (1), 37 (2018).] Crossref

9. G.P. Anastasiadi, S. Yu. Kondratyev, M. V. Sil'nikov. St. Petersburg Polytechnic University Journal of Engineering Science and Technology. 2 (243), 99 (2016). (in Russian) [Г.П. Анастасиади, С.Ю. Кондратьев, M.В. Сильников. Научно-технические ведомости СПбГПУ. 2 (243), 99 (2016).] Crossref

10. V.M. Salganik, D.N. Chikishev, E. B. Pozhidaeva, D. G. Nabatchikov. Metallurgist. 59, 766 (2015). $\underline{\text { Crossref }}$ 11. O. V. Sych, A. A. Kruglova, E. I. Khlusova, V. V. Orlov. Stal'. 1, 56 (2013). (in Russian) [О.В. Сыч, А.А. Круглова, Е. И. Хлусова, В. В. Орлов. Сталь. 1, 56 (2013).]

12. I. V. Egiz, V. F. Shamrai. Metal Science and Heat Treatment. 43 (1-2), 51 (2001). Crossref

13. I. V. Egiz, V. F. Shamrai. Metal Science and Heat Treatment. 45 (1-2), 35 (2003). Crossref

14. N.M. Shkatulyak, E.N. Tkachuk. Physics and high pressure technology. 22 (1), 107 (2012). (in Russian) [Н.М. Шкатуляк, Е.Н. Ткачук. Физика и техника высоких давлений. 22 (1), 107 (2012).]

15. M.M. Borodkina, E. N. Spector. Rentgenograficheskiy analiz tekstur v metallakh i splavakh. Moscow, Metallurgiya (1982) 272 p. (in Russian) [M.M. Бородкина, Э.Н. Спектор. Рентгенографический анализ текстур в металлах и сплавах. Москва, Металлургия (1982) 272 с.]

16. N. P. Lyakishev, V.F. Shamray, E. B. Rubina. Metally. 5, 22 (1995). (in Russian) [Н. П. Лякишев, В. Ф. Шамрай, Е. Б. Рубина, и др. Металлы. 5, 22 (1995).] 